\title{
RHINO-ORBITO-CEREBRAL MUCORMYCOSIS (BLACK FUNGUS) IN COVID 19 PATIENTS
}

\author{
Authors: Keshav Gupta (1) Mohit Srivastava* (2), Veenita Singh (3) \\ Authors Affiliations: (1) Senior Resident, (2) Professor\& Head, Department of ENT, GSMCH Hapur Uttar \\ Pradesh, (3) Professor Oral \& Maxillo-Facial Surgeon; Dy Patil University Mumbai Maharashtra.
}

\begin{abstract} BACKGROUND

Mucormycosis (Black fungus) is a designated as a rare, rapidly progressive fatal disease of immunocompromised caused by saprophytic fungus of family mucorales. Early diagnosis with prompt medical and surgical treatment is the only tool available. Rhino-orbito-cerebral is the most common subtype. In India we saw a sudden rise in mucormycosis cases during second wave of COVID 19. This necessitated a systematic review of epidemic of mucormycosis in COVID 19.
\end{abstract}

\section{METHODS}

A Retrospective multi-centric study was conducted at various Government and Private Hospitals of Western UP comprising of 51 cases of Rhino-orbitocerebral mucormycosis with present or recent COVID19 positive status presenting to us during 14th April 2021-31st May 2021.

\section{RESULT}

Either Type2 Diabetes Mellitus or history of recent use of steroids in high doses was present in all the patients. Contribution of virulence of the Delta strain B1.617.2 is significant. FESS with sino-nasal debridement contributes significantly towards mortality reduction and cost of total treatment by significantly reducing days of Liposomal Amphotericin B therapy.

\section{CONCLUSION}

Early diagnosis with prompt medical and surgical management along with blood sugar control and avoiding use of high dose of steroids remain to key to mortality and morbidity reduction.

Keywords: Black fungus, mucor, mucormycosis, rhino-orbito-cerebral, causes, treatment, covid 19,
India, sugar, steroids, steam, oxygen, surgery.

Funding: None

\section{Conflicts of interest: None}

\section{INTRODUCTION}

Mucormycosis are a group of invasive infections caused by filamentous fungi of the Mucoraceae family1. It is the third invasive mycosis in order of importance after candidiasis and aspergillosis2. The incidence of mucormycosis is approximately 1.7 cases per 1000000 inhabitants per year, and the main risk-factors for the development of mucormycosis are ketoacidosis (diabetic or other), iatrogenic immunosuppression, use of corticosteroids or deferoxamine, disruption of mucocutaneius barriers by catheters and other devices, and exposure to bandages contaminated by these fungi 2 .

Rhino-orbito-cerebral is the most common clinical subtype of disease. Mucormycosis is a difficult to diagnose rare disease with high morbidity and mortality3. This form presents with sinusitis, facial and eye pain, proptosis, progressing to signs of orbital structure involvement4,5,6,7. Necrotic tissue can be seen on nasal turbinates, septum and palate. This may look like a black eschar7,8,. Intracranial involvement develops as the fungus progresses through either the ophthalmic artery, the superior fissure, or the cribiform plate 4,7.

Diagnosis of mucormycosis rests upon the presence of predisposing conditions, signs and symptoms of disease, observation of fungal elements of specific morphology in histological sections, and direct smears of material, and, to a lesser extent, culture results6,7. There are no reliable serological tests for diagnosis at present8. 
The incidence of mucormycosis has risen more rapidly during the second wave compared with the first wave of COVID 19 in India, with atleast 28,252 mucormycosis cases on 7th June 2021. $86 \%$ of them are known to have history of COVID 19 and $62.3 \%$ of them are known to be diabetic 9 .

\section{AIM}

To study various risk factors, clinical features, diagnosis, treatment and outcome of mucormycosis patients during second wave of COVID 19 in Western UP in India.

\section{STUDY DESIGN}

This is a Multi-centric Retrospective study. The retrospective data was collected from various Government and Private Institutes in Western UP. SAMPLE SIZE

No of cases- 51

Study period-14th April 2021- 31st May 2021

INCLUSION CRITERIA

All the following criteria was satisfied

Patient presented during 14th April 2021 midnight- 31st May 2021 midnight.

COVID 19 RT PCR positive at any time during the study period or within 28 days before beginning of study period.

Biopsy proven mucormycosis and/or patient had features clinically consistent with diagnosis of mucormycosis, that is, two or more of following on presentation:

Black eschar within oral cavity and/or blackish eschar within nasal cavity and/or blackish eschar over face

Severe facial pain and facial swelling of onset within last 28 days

Eye swelling and/or Ptosis and/or proptosis

Computerized tomography or magnetic resonance and imaging suggestive of invasive fungal rhinosinusitis

\section{EXCLUSION CRITERIA}

Oral and sino-nasal malignancies, other conditions associated with oro-mucosal ulcerations, absence of present or recent COVID 19 status.

\section{MATERIAL AND METHODS}

After all inclusion and exclusion criteria were satisfied, records were checked for presence and absence of various predisposing factors, treatment offered, histopathology reports, surgeries performed and outcome.

All the data was gathered and tabulated in Microsoft Excel 2008 spreadsheet. SPSS 24 was used for statistical calculations. Results were systemized and summarized.

\section{OBSERVATIONS}

\begin{tabular}{|c|c|}
\hline Sex & No of cases \\
\hline Male & 28 \\
\hline Female & 23 \\
\hline Total & 51 \\
\hline
\end{tabular}

Table 1.1: Sex distribution of cases

Male to female ratio is $1.21: 1$ which is not a significant difference $(p<0.05)$

\begin{tabular}{|c|c|}
\hline Age distribution & No of cases \\
\hline Less than 31 & 2 \\
\hline $31-45$ & 22 \\
\hline $46-60$ & 18 \\
\hline More than 60 & 9 \\
\hline Total & 51 \\
\hline
\end{tabular}

Table 1.2: Age distribution of cases Out of 51 patients, 22 belonged to age group 3145 which is a significant value $(p>0.05)$

\begin{tabular}{|c|c|}
\hline COVID Status & No of cases \\
\hline Active COVID & 25 \\
\hline Post COVID & 26 \\
\hline Total & 51 \\
\hline
\end{tabular}

Table 1.3: COVID status of patients Out of 51 patients, 25 had active COVID infection which is not a significant difference $(p<0.05)$

\begin{tabular}{|l|c|c|}
\hline \multicolumn{1}{|c|}{ Risk Factor } & $\begin{array}{c}\text { No. of } \\
\text { cases }\end{array}$ & Association \\
\hline Diabetic & 43 & Strong \\
\hline Recent history of Steroids & 49 & Strong \\
\hline Either Diabetes or steroids & 51 & Definitive \\
\hline Oxygen support & 16 & Weak \\
\hline History of Tocilizumab & zero & Can not comment \\
\hline $\begin{array}{l}\text { Steam inhalation more } \\
\text { than one hour a day }\end{array}$ & 1 & Absent \\
\hline
\end{tabular}


Table 1.4: Various Risk Factors for mucormycosis with Delta stain of COVID 19 noted in our study All the patients of mucormycosis with COVID19 were either diabetics or had taken steroids or both were present. So, there is a definitive association of mucormycosis with these two risk factors.

Independently, there is a strong association between mucormycosis in COVID19 patients with steroids and diabetes.

However, strong association of mucormycosis in COVID19 patients with oxygen therapy is found to be lacking.

There is no association between steam therapy and mucormycosis in COVID19 patients.

Since, no patient with history of Tocilizumab administration is included in our study, Effect of Tocilizumab administration on mucormycosis cannot be commented from our study.

\begin{tabular}{|l|c|c|}
\hline Clinical Feature & $\begin{array}{c}\text { No. of } \\
\text { cases }\end{array}$ & Frequency \\
\hline Eye swelling & 34 & 66.67 \\
\hline Diminished vision & 29 & 56.86 \\
\hline Ptosis & 28 & 54.90 \\
\hline Black eschar & 25 & 49.02 \\
\hline Facial swelling & 23 & 45.10 \\
\hline Proptosis & 18 & 35.29 \\
\hline Facial pain & 16 & 31.37 \\
\hline Loss of vision & 11 & 21.57 \\
\hline Nasal discharge & 8 & 15.69 \\
\hline Nasal bleed & 4 & 7.84 \\
\hline Altered sensorium & 1 & 1.96 \\
\hline
\end{tabular}

Table 1.5: Clinical features in 51 patients of mucormycosis with COVID 19

Eye swelling is seen to be the most consistent clinical feature in mucormycosis with COVID 19 present in two-thirds of patients followed by diminished vision (57\%) and ptosis (55\%). Overall, ocular symptoms are more common when patients are co-infected with COVID19 when compared to mucormycosis alone.

Image 1.1 : Clinical features of mucormycosis. Clockwise: Facial swelling, oral cavity eschar, eye swelling, facial eschar, congestion, diminished vision and ptosis of eyes.

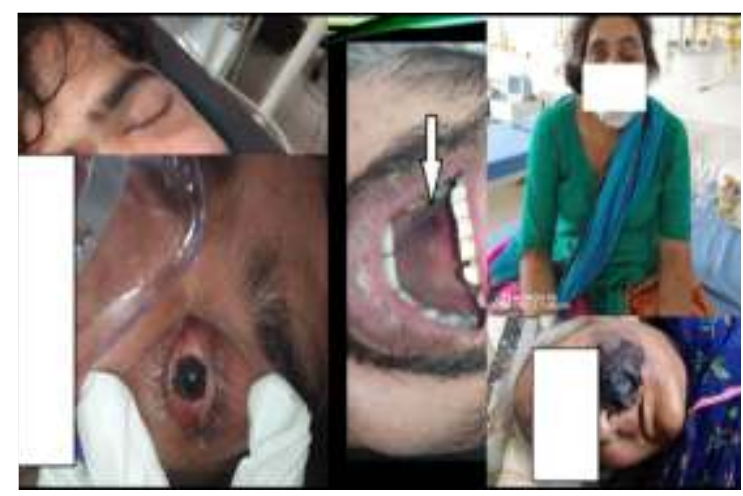

Image 1.2: Computerised tomography.

a. Rt maxillary sinus non-hemogenous opacification b. Rt orbital involvement with proptosis

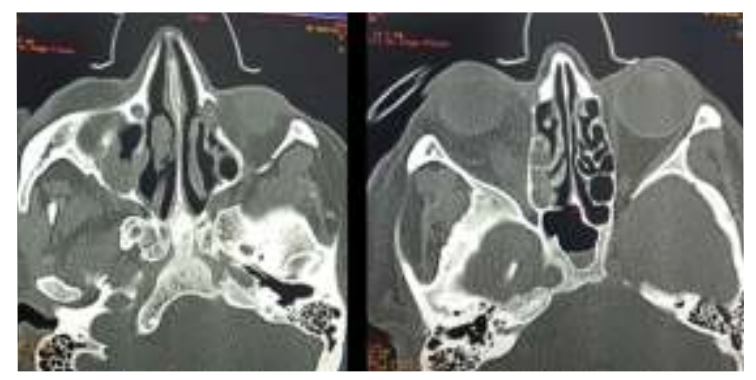

Figure 1.2 : Computerized tomography scan showing a. Non homogenous opacification of Rt Maxillary sinus b. Rt orbital involvement with proptosis

Table 1.6: Outcome in 51 patients of mucormycosis with COVID19

\begin{tabular}{|c|c|c|}
\hline Outcome & No. of patients & Frequency \\
\hline $\begin{array}{c}\text { Recovered during study } \\
\text { period }\end{array}$ & 18 & 35.29 \\
\hline $\begin{array}{c}\text { Survived but did not recover } \\
\text { during study period }\end{array}$ & 23 & 45.10 \\
\hline Facial disfigurement & 4 & 7.84 \\
\hline $\begin{array}{c}\text { Permanent loss of vision } \\
\text { from one eye }\end{array}$ & 3 & 5.88 \\
\hline $\begin{array}{c}\text { Permanent loss of vision } \\
\text { from both eyes }\end{array}$ & 1 & 1.96 \\
\hline \begin{tabular}{c} 
Expired during study period \\
\hline
\end{tabular} & 10 & 19.61 \\
\hline
\end{tabular}

80 percent of patients survived the study period and almost half of them recovered completely 
during study period itself. Out of 51 patients, 4 suffered from facial disfigurement because of the disease, 4 had permanent loss of vision from one or both eyes.

Table 1.7: Treatment offered in terms of Liposomal Amphotericin B and Debridement surgery to various patients

\begin{tabular}{|c|c|c|}
\hline Treatment given & No of patients & Frequency \\
\hline $\begin{array}{c}\text { Liposomal Amphotericin B } \\
\text { for 1-7 days }\end{array}$ & 35 & 68.63 \\
\hline $\begin{array}{c}\text { Liposomal Amphotericin B } \\
\text { for 8-14 days }\end{array}$ & 11 & 21.57 \\
\hline $\begin{array}{c}\text { Liposomal Amphotericin B } \\
\text { for more than 14 days }\end{array}$ & 1 & 1.96 \\
\hline Debridement surgery & 34 & 66.67 \\
\hline
\end{tabular}

Two-thirds of patient underwent debridement surgery. In almost same number of patients, Liposomal Amphotericin B was required for 1 week or less. All other patients required longer treatment with Amphotericin B.

Image 1.3: A. Black Eschar in Nasal Cavity. B. Debrided Remnant of Middle Turbinate. C. Post Debridement Image.

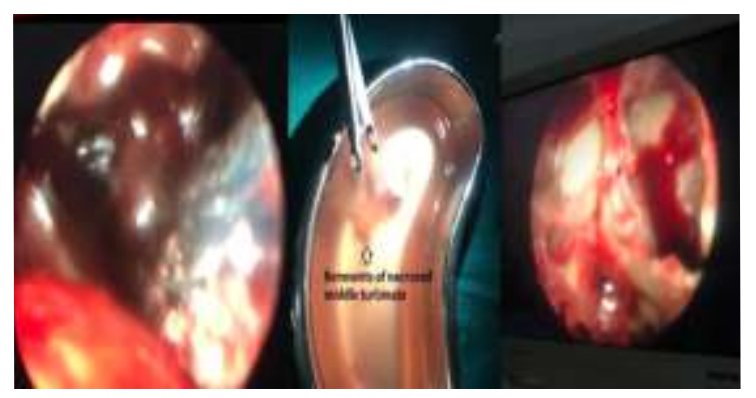

Table 1.8: Number of patients who took surgery charted with number of patients who survived the study period

\begin{tabular}{|c|c|c|c|}
\hline Surgery and survival & $\begin{array}{c}\text { No of patients } \\
\text { who took } \\
\text { surgery }\end{array}$ & $\begin{array}{c}\text { No of patients } \\
\text { who did not take } \\
\text { surgery }\end{array}$ & $\begin{array}{c}\text { Total } \\
\text { patients }\end{array}$ \\
\hline $\begin{array}{c}\text { No of patients survived } \\
\text { during study period }\end{array}$ & 32 & 9 & 41 \\
\hline $\begin{array}{c}\text { No of patients expired } \\
\text { during study period }\end{array}$ & 2 & 8 & 10 \\
\hline Total patients & 34 & 17 & 51 \\
\hline
\end{tabular}

Almost one-third of patients undertook debridement surgery and majority of them survived the study period. 9 out of 51 patients could not be operated either because of early mortality because of disease or because of no consent for surgery from patient. Only one of them could survive through the study period. This difference in survival ratio amongst operated and non-operated patients is significant $(p>0.05)$

\begin{tabular}{|l|l|}
\hline $\begin{array}{l}\text { Duration of } \\
\text { Amphotericin B }\end{array}$ & $1-45$ days \\
\hline With Surgery & $1-7$ days \\
\hline Without surgery & $1-45$ days \\
\hline
\end{tabular}

Table 1.9: Effect of surgery on duration of Amphotericin B therapy and hence cost of treatment

Also surgery led to reduction in duration of Amphotericin B therapy from 1-45 days to 1-7 days.

\begin{tabular}{|c|c|}
\hline $\begin{array}{c}\text { Duration from } \\
\text { presentation }\end{array}$ & $\begin{array}{c}\text { No of patients } \\
\text { who expired }\end{array}$ \\
\hline Within 24 hours & 4 \\
\hline 24-48 hours & 2 \\
\hline $48-72$ hours & 3 \\
\hline More than 120 hours & 10 \\
\hline Total & 1 \\
\hline
\end{tabular}

Table 1.10: Figures of mortality from the time of presentation 
Maximum mortality was seen within 24 hours of presentation which reduced subsequently on second and third day.

\section{RESULT}

The disease is equally seen in both sexes. The disease is exclusively seen in either diabetics or those who have recently taken steroids. Immunocompromised patients with Delta stain of COVID 19 Pango lineage B.1.617.2 have more risk of developing mucormycosis than their non COVID counterparts. Oxygen inhalation also contributes to the risk. There is no positive or negative effect of steam inhalation.

There is an increase in no of cases of mucormycosis because of delta strain of COVID 19. There is a shift of peak towards the younger age groups. There is increased frequency of eye involvement. Mortality is maximum within first 72 hours of presentation. However, mortality ratio is less when co-infected with delta strain of COVID 19.

Surgery offers significant benefit by decreasing mortality, decreasing duration of Liposomal Amphotericin B treatment and hence reducing cost of treatment.

\section{CONCLUSION}

Delta strain of COVID 19 has significantly increased the incidence of mucormycosis due to its immunosuppressive effect. Excessive use of steroids has also contributed to the same. Since, patients of younger age group are affected more with this strain, the peak of mucormycosis has also shifted in the same direction. In a young patient with unatherosclerosed and more patent vessels, there is early involvement of ethmoid and opthalmic vessels and hence early necrosis of turbinates is seen alongwith prominent eye symptoms. The massive coverage of black fungus by media has made people extra conscious about the mucormycosis, which has also contributed to early presentation and early diagnosis of the disease10. Early diagnosis coupled with early surgery in younger patient may have contributed to lower mortality when recorded over a short time span.

\section{REFRENCES}

1. Mallis A, Mastronikolis SN, Naxakis SS, Papadas AT. Rhinocerebral mucormycosis: an update. European Review for Medical and Pharmacological Sciences. 2010; 14: $987-$ 992.

2. Bouza E, Munoz P, Guinea J. Mucormycosis: an emerging disease? Clinical Microbiology and infection 2006;12(7):7-23.

3. Global guideline for the diagnosis and management of mucormycosis. Available at: https:doi.org/10.1016/S1473-3099(19)303123. Accessed on May 27,2021.

4. Strickland GT. Hunter's Tropical Medicine. Philadelphia, PA: WB Saunders. 1984:468469.

5. Koneman E, Allen S. Diagnostic Microbiology. Philadelphia, PA: JB Lippincott. 1992:812-814.

6. Mucormycosis (Zygomycosis). Available at: http://www.emedicine.medscape.com/oph/t opic225.htm. Updated Sep10,2018. Accessed May27,2021.

7. Branscomb R. An overview of mucormycosis. CE Update microbiology and virology. 2002;33(6):1-3.

8. Rippon J. Medical mycology. Philadelphia, PA: WB Saunders. 982:615-637.

9. Black Fungus: These 2 states account for nearly $42 \%$ of India's 28252 mucormycosis cases. June 7,2021. Available at: https://www.livemint.com/news/india/blackfungus/amp-11623069135171.htm.

10. India's Black Fungus Epidemic Spread Through Hospital Air Conditioning, New Research Suggests. Available at: https://scroll.in/article/1010105/indias-blackfungus-epidemic-spread-through-hospitalair-conditioning-new-research-suggests. htm.

\footnotetext{
*Corresponding Author -

Dr. Mohit Srivastava,

Professor \& Head ENT, GSMCH, Hapur Uttar Pradesh.

Mob-9999556665 / dr.mohit141180@gmail.com
} 